\title{
DO DISCURSO DO AGENTE DO OUTRO À VOZ-APELO DO SUJEITO
}

\author{
Amanda Schreiner Pereira* \\ Universidade Federal de Santa Maria \\ Universidade Luterana do Brasil \\ Santa Maria, RS, Brasil
}

Angela Maria Resende Vorcaro* Universidade Federal de Minas Gerais Departamento de Psicologia Belo Horizonte, MG, Brasil

Marcia Keske-Soares ${ }^{\star \star *}$ Universidade Federal de Santa Maria Departamento de Fonoaudiologia Santa Maria, RS, Brasil

\begin{abstract}
Resumo: Este artigo é um estudo teórico-crítico psicanalítico embasado na leitura da obra de Freud e de Lacan e nos recortes empreendidos pelas autoras para associar a origem da voz-apelo do sujeito ao discurso do agente do Outro, sustentado pela lógica da linguagem. Dos endereçamentos do agente do Outro, destaca a expulsão do timbre, a afirmação da voz prosódica materna, e a instauração da primeira matriz simbolizante no infans. Com isto, posiciona o sujeito, desde os primórdios, pela relação com o discurso materno e enfatiza a passagem dos vagidos iniciais à voz que faz apelo, mediante o engajamento no laço com o Outro.
\end{abstract}

Palavras-Chave: Discurso. Outro. Voz. Sujeito.

Este artigo se embasa na concepção lacaniana de linguagem, no que Lacan (1998/1964) localiza a "Precedência do lugar Outro", relativa ao campo no qual estão

\footnotetext{
* Doutora em Distúrbios da Comunicação Humana pela Universidade Federal de Santa Maria (UFSM). Psicóloga do Curso de Psicologia da UFSM. Professora do curso de pós-graduação Clínica Psicanalítica da Universidade Luterana do Brasil - Campus Santa Maria. E-mail: psico_amanda@hotmail.com.

** Doutora em Psicologia pela Pontifícia Universidade Católica de São Paulo. Professora Associada (aposentada-voluntária) do Departamento de Psicologia da UFMG. E-mail: angelavorcaro@uol.com.br.

*** Doutora em Linguística Aplicada pela Pontifícia Universidade Católica do Rio Grande do Sul. Professora Titular do Departamento de Fonoaudiologia e do Programa de Pós-Graduação em Distúrbios da Comunicação Humana da UFSM. E-mail: marcia-keske.soares@ufsm.br.
} 
inseridos os provedores dos primeiros endereçamentos vocais e dos significantes àqueles que nascem, antes que estes possam ser distinguidos. Ao delimitar o lugar Outro e seus efeitos discursivos, capazes de transcrever o mundo sobre o corpo infans, parte de um tempo em que o sujeito só é suposição no Outro, agenciada pelos agentes parentais, para chegar aos desdobramentos dessas suposições e dos endereçamentos a ela relativos.

Do agente do Outro teremos a oferta do objeto da necessidade; a demanda, na transformação do grito em apelo; e a lógica da linguagem, pelos modos como assegura os atributos diferenciais do apelo, dando início à vida anímica. Em seguida, o escrito leva às "Incursões do primeiro grito", perfazendo o caminho desde o estado de desamparo ao nascimento e a experiência com o próximo assegurador (Nebenmensch), até a instauração dos objetos pulsionais, e a relação com o outro. Lembrando que, para Freud (2015/1915), as pulsões têm apoio nas funções vitais e são estas que recebem novo estatuto a partir do desenrolar da visa anímica, e que o desamparo psíquico do bebê é a contrapartida evidente de seu desamparo biológico (FREUD, 2014/1926), o trabalho problematiza a função relativa à voz enquanto objeto pulsional, a qual determinaria o interesse precoce dos bebês pela voz sonorizada materna.

$\mathrm{Na}$ seção "Tropismo de voz e acionamento vocal", o escrito trabalha a voz prosódica materna e o enganche prosódico denotativo da apetência simbólica, diferenciando-o da apetência sonora, e lança a hipótese da expulsão do timbre para que a apetência simbólica opere. Com isso, também aposta que a origem da voz-apelo se dá mediante a temporalidade ritmada que inaugura a condição de subjetivação. Para tanto, localiza o despontar da voz como apelo na pressa, na seção "Voz-apelo".

\section{PRECEDÊNCIA DO DISCURSO DO OUTRO}

A origem do sujeito precede o nascimento, essa é a primeira prerrogativa pela qual nos embasaremos - através da Psicanálise - em sua fundação teórico/clínica por Sigmund Freud e na releitura e no aprofundamento de Jaques Lacan. Essa precedência é relativa ao campo da linguagem, no qual estão inseridos os sujeitos que assumirão a função de provedores dos primeiros endereçamentos vocais e dos significantes àqueles que nascem.

Mesmo antes de nascer, o bebê é falado, projetado e esperado. Isso organiza um campo, uma pré-história constituída de redes de sentidos, forças iniciais prévias a qualquer experiência. Essa pré-história podemos observar no discurso parental: meu filho se chamará "x", porque “x.........." significa “y..........". Ele se parecerá com “........”; cada pai, mãe ou substituto irá preencher essas lacunas conforme suas particularidades. Dizemos pai, mãe ou substituto porque, independentemente da pessoa que assumirá o lugar de endereçamento da pré-história ao bebê, o que conta é a sua função, função essa denominada Outro por Lacan (1998/1964).

O Outro primordial é o portador dos primeiros significantes que serão endereçados por meio do campo discursivo ao infans, aquele que ainda não fala. O campo do Outro já está lá, antes que o infans venha ao mundo, e é o lugar de onde o sujeito se constitui. Valendo-se desse lugar, o agente do Outro opera interpretações sobre o pequeno ser que nasce e comanda o que se presentifica como sujeito. 
Temos, assim, o agente do discurso e o que esse agente produz em seu discurso sobre o pequeno ser que nasce, de modo que o Outro radicalmente primário ofertará condições para que o infans possa se constituir sujeito. Vejamos de que modo operam os efeitos discursivos. Sabemos que, logo após o nascimento, a partir da função interpretativa do agente do Outro, a cada coisa que o bebê faz, recebe uma significação. Ao significar o que ainda não tem significado, o agente do Outro transcreve o mundo no corpo infans. Essa transcrição se dá de modo muito peculiar - a mãe transitiva.

O transitivismo é um processo primordial por meio do qual uma criança ascende ao afeto pela afetação do agente do Outro. Em seu estudo sobre o transitivismo, Bergès e Balbo (2002) apoiam-se no fenômeno em que uma mãe, ao ver o filho cair sem exprimir dor, experiencia e comunica, por meio da fala, a dor que sente nela mesma. Com isso, a mãe sustenta seu afeto comunicando uma certeza, de modo que seu filho lhe dá razão, passando a sentir dor.

De início, podemos dizer que a condição real a qual está submetido o agente materno é recortada desde o lugar Outro, que sustenta sua fala e seus atos em direção ao infans ordenado pela linguagem.

Assim, o agente do Outro supõe o que a criança experimenta referenciando-se num discurso sobre o sofrimento dela, por exemplo: na emissão de um "ai" bem entonado; ao mesmo tempo em que esta experiência afeta seu próprio corpo, estabelecendo a ternariedade do Outro. Trata-se do terceiro termo que, em Bergès e Balbo (2002), vemos introduzir-se com o transitivismo por meio da formulação das hipóteses atribuídas ao filho pelo discurso materno.

As antecipações discursivas do agente são extremamente precoces. Ainda grávida, uma mãe supõe demandas a seu filho, e, sobre essas demandas, sustenta-se todo um diálogo. Ela verbaliza e dá sentido aos movimentos motores intrauterinos, experienciados em seu próprio corpo (BERGÈS; BALBO, 2002).

Com Freud (2014/1926), entendemos que há mais relação de continuidade entre a vida intrauterina e a primeira infância do que a ruptura do nascimento poderia nos suscitar. Salientando que, na vida intrauterina, não há objetos para o feto e que, portanto, a mãe não era um objeto, o psicanalista esclarece que este futuro objeto psíquico, ao exercer função materna tenta substituir, para a criança, a situação biológica parasitária do feto. É por operar essa substituição que o objeto materno será constituído como tal pela criança, neste primeiro tempo apenas suposta sujeito pelo agente da função materna. Esta suposição, originada no desejo Outro, cuja função é ocupada por um agente capaz de ler o corpo do bebê, é o que permite que sejam realizadas leituras do agente sobre as manifestações infans. Atentaremos a estas leituras.

\section{INCURSÕES DO PRIMEIRO GRITO INFANS}

No texto Inibição, Sintoma e Angústia, ao tocar numa área fronteiriça da fisiologia - a origem de todos os afetos -, Freud (2014/1926) afirma que os estados afetivos incorporaram-se à psique precipitados de vivências antiquíssimas, dentre elas, o nascimento. Ele escreve que a forma com que o bebê reage ao nascimento, através de manifestações vocais - choro - relativo à atividade dos pulmões para eliminação dos estímulos internos, incitará reações posteriores do bebê (FREUD, 2014/1926). 
Quase trinta anos antes, no Projeto para uma psicologia científica, Freud (1996/1895) já apontara que a primeira expressão do infans, em sua condição de prematuração humana, seu estado de insuficiência, é a descarga da tensão orgânica por meio de um grito. Esse grito é uma forma de se afastar da experiência dolorosa ocasionada pela ruptura do equilíbrio homeostático vivido pelo bebê em seu meio fetal.

Diante deste desprendimento de energia do mundo interior infans, em forma de grito, interviria uma alteração no mundo exterior a fim de eliminar temporariamente essa manifestação. Para Freud (1996/1895), essa intervenção sobrevém mediante auxílio alheio do próximo assegurador (Nebenmensch). Ela se dá, por exemplo, pela provisão de alimento. Isso porque, diante do que estamos chamando de primeiro grito, o agente também se angustia, tomando o grito como apelo a si e sentindo-se compelido a responder.

Nesse ato de oferecimento, está claro que o outro, agente da função materna, lê o grito como uma demanda a si, o agente é quem pode ofertar o objeto da necessidade. Chamamos esse outro de agente da função materna, visto que "o que é próprio no exercício da função materna é o trabalho de recobrir o real do organismo do bebê" (JERUSALINSKY, J., 2004, p. 220).

Todavia, na oferta do outro, podemos já delimitar uma duplicidade de objetos. De um lado, o alimento, objeto da satisfação da necessidade; de outro, o seio, fonte de apaziguamento. Temos aqui um objeto ligado à sua função biológica e outro ligado ao corpo do agente, na oferta de apaziguamento-satisfação. Para Freud (2016/1900), a imagem mnemônica da percepção particular da experiência de satisfação associa-se ao traço de memória da excitação produzida pela necessidade, permitindo que o ressurgimento da necessidade reinvista tal imagem e evoque alucinatoriamente a percepção para reestabelecer a situação da satisfação original, considerada como retorno à homeostase.

Essa atividade psíquica leva à identidade perceptiva, repetição da percepção que está enlaçada com a satisfação da necessidade. Isso já havia sido proposto por Freud (1996/1895), quando afirmou que a insuficiência da atividade primitiva, em que perdura a tensão do estado de necessidade, obriga a uma atividade secundária que inibe esta curta via regressiva e que desvia as excitações para caminhos que conduzam, a partir do exterior, ao reestabelecimento da identidade perceptiva.

Esse caminho, que ele retoma em A Interpretação dos Sonhos (FREUD, 2016/1900), tem o caráter da ação específica que funda o princípio da repetição cuja finalidade é a reprodução do estado inicial. O infans se esforça para fazer retornar suas experiências em seu próprio corpo, mas, diante de traços novos e incomparáveis, há irredução a si mesmo e se constitui um fundo organizado e estável do Outro, fora da representação: a Coisa (das Ding). Para Lacan (2008, 1959-60), a Coisa é um lugar central, uma exterioridade íntima, para o qual utiliza o neologismo extimidade. Vale lembrar que Extimo refere-se ao "mais íntimo, o mais particular, o mais interior, mas que está excluído, fora.” (SEGANFREDO; CHATELARD, 2014, p. 63).

Observamos que, na experiência com o próximo assegurador (Nebenmensch), como define Freud, a Coisa é o elemento originalmente isolado pelo infans, um interior excluído (LACAN, 2008/1959-60). Por outro lado, se origina o complexo perceptivo do próximo, onde sinais perceptivos são convocados para o registro da perda do objeto da necessidade (FREUD, 1996/1895). 
Esse complexo perceptivo do outro assegurador é divido, então, em dois componentes: ele é uma Coisa êxtima, mas também é compreendido por um trabalho mnêmico. Quinet (2004) esclarece que a Coisa não pode ser conhecida porque não é apreendida pela percepção, ela é independente de nossos sentidos, de modo que não pode ser objeto nem da experiência, nem da representação. Registramos que essa Coisa, então, é inapreensível à própria percepção auditiva. Quanto ao segundo, uma parte do complexo perceptivo do outro semelhante sofre uma primeira transcrição e é reconduzido a uma informação do próprio corpo (FREUD, 2016/1896).

Sendo a Coisa (das Ding) um elemento isolado, perguntamo-nos de que modo algo é excluído do interior de um sujeito hipotético. No texto sobre a Negativa, no qual Freud (2011/1925) retoma a diferença entre a criança e o mundo externo, encontramos elementos para assinalar que é por meio de uma apreciação judicativa, uma apreciação responsável pela primeira transcrição, que líamos na carta freudiana (FREUD, 2016/1896), e da qual se subtrai um resto refratário à apreensão.

O trabalho de Freud sobre a apreciação judicativa remonta às origens da função do julgamento diante de duas espécies de decisões. Na primeira, o julgamento afirma ou desafirma um atributo particular a uma coisa, ela é boa ou má. Sua expressão reside na oralidade, segundo Freud (2011/1925), da seguinte forma: gostaria de botar isso para dentro de mim, na forma "comer isso", ou gostaria de manter aquilo fora de mim, cuspilo fora. Essa atividade é relativa ao prazer-desprazer, ou seja, à homeostase (apaziguamento)-tensão.

Conseguimos, dessa forma, situar o que pode ser "colocado para dentro e para fora". Para Freud (2011/1925), o princípio da vida anímica é regulada pelo princípio de prazer entendido como homeostase, ou seja, o organismo deseja introjetar para dentro de si tudo quanto é bom (que apazigua) e ejetar de si tudo quanto é mau, que lhe é estranho (que lhe causa tensão), de início idêntico ao que lhe é externo. Esse é o tempo em que se repartem os objetos, em que há o objeto "bom para mim", (idêntico a mim, eu mesmo) e o objeto resto, objeto estranho (idêntico ao que é exterior a mim), mediante o juízo de atribuição.

Interessa observar que Freud, em 1925, situa o "bom" como o que é colocado para dentro e o "mau" como o que é ejetado por via da expulsão primária (Ausstossung), antecessora da negação. A expulsão primária (Ausstossung) responde pela constituição do fora como real, exterior jamais representável, um mito de origem que supõe preexistir o que ele supostamente constitui.

Só posteriormente o sujeito poderá tomar o que causa tensão e desprazer (uma exterioridade já internalizada como coisa ainda irrepresentável) como alvo de seu interesse. É o que Freud (2010/1920) explicita em Além do princípio do prazer ao problematizar a repetição de vivências dolorosas insistentemente retomadas em brincadeiras infantis e nos sonhos de guerra dos soldados. Lacan (1998/1964) lhe acrescentará precisão ao situar, como real, o núcleo que Freud qualificou como traumático, originalmente mal vindo. Este, insabido, irrepresentável, se tornará o maior cúmplice da pulsão (que o contorna), fazendo bater a pulsação que a reconhece a cada repetição.

Diante da mutilação primitiva, da expulsão primária (Ausstossung), assevera-se o segundo julgamento, que discute a existência na realidade de uma representação. $O$ julgamento de existência decide quanto à existência de algo na realidade, operando uma 
espécie de teste. Para Freud (2010/1911), com esse "teste de realidade" contempla-se o início do domínio do princípio de realidade.

Como consequências do princípio de realidade, novas exigências tornam necessárias adaptações do aparelho psíquico. Vejamos quais. A maior significação da realidade externa eleva a qualificação dos órgãos dos sentidos voltados ao mundo externo e à consciência a eles vinculada. É estabelecida a função atenção para exame periódico do mundo exterior e identificação de dados já conhecidos. Para isso, é instituído um sistema de registro, para guardar os dados dessa periódica tarefa da consciência, parte do que constitui a memória.

O juízo de existência passa a resolver se uma ideia concorda com a realidade, por comparação aos traços de memória da realidade. Por fim, a descarga motora, que aliviava o aparelho psíquico por meio de inervações enviadas ao interior do corpo - mímica, expressões de afeto - "recebeu uma nova função, ao ser utilizada na modificação adequada da realidade. Transformou-se em ação" (FREUD, 2010/1911, p. 113). As características do pensar permitiram suportar a tensão dos estímulos mediante a suspensão da descarga. Freud (2010/1911) diz ser provável que o pensar se voltou para as relações entre as impressões de objetos, adquirindo qualidades perceptíveis à consciência mediante a ligação a resíduos verbais.

Em resumo, para Freud (2011/1925), o julgamento de existência denota um interesse na realidade e julga se uma representação pode ser redescoberta, também, na percepção/realidade, sendo que aqui a consideração pelo princípio de prazer foi posta de lado. Afinal, o julgamento de existência implica a introdução de processos secundários, vinculados à atenção ao mundo externo e, portanto, à consciência, e não apenas a processos primários inconscientes. Assim, não somente é importante ao sujeito que um objeto de satisfação receba o atributo de bom, mas que, ainda, possa ser reencontrado no mundo externo para que o sujeito possa se apossar dele sempre que necessitar.

Temos, aqui, o engajamento representativo do infans que busca o reencontro com o objeto. Do objeto para sempre perdido freudiano, teremos objetos substitutos que só reinscrevem seu estatuto diferencial para com a satisfação mítica que deu origem à série, balizando o contorno desta falta inassimilável (VORCARO, 1997). De que objetos se trata?

Dissemos que, no princípio, há apoio em uma função vital. Também trouxemos a área fronteiriça à fisiologia, que Freud pôde desenvolver em sua teoria sobre os afetos. Essas fronteiras são oriundas da própria formação de Freud, a Neurologia, subvertida pela criação da Psicanálise. Vamos introduzir, agora, a pulsão (Trieb), sobre a qual advém a busca pelo reencontro objetal, enfatizando que é a função vital que receberá novo estatuto a partir do desenrolar da vida anímica. A pulsão é um conceito fronteiriço entre o anímico e o somático. A pulsão é como "uma medida da exigência de trabalho imposta ao anímico em decorrência de sua relação com o corporal" (FREUD, 2015/1915, p. 25).

No texto sobre o narcisismo, Freud (2014/1914) já enfatizava que as primeiras satisfações, as autoeróticas, são vivenciadas em conexão com as funções vitais sobre as quais se apoiam as pulsões no início. $\mathrm{O}$ fato de as pessoas que lidam com a alimentação e o cuidado da criança serem os primeiros objetos de investimentos da mesma é um resquício dessa conexão. 
Já situamos que Freud (2015/1915) compreende o neonato, em seus primeiros dias, como um ser desamparado, que recebe estímulos sobre sua substância nervosa. O sistema nervoso tem como primeira tarefa o domínio dos estímulos. Em breve o ser vivo passará por uma primeira diferenciação: de um lado, perceberá os estímulos externos que podem ser afastados por uma ação; de outro, evidenciará a existência de estímulos internos, por sua vez constantes. Dessa forma, a primeira diferenciação da atividade perceptiva é a capacidade de discernir dentro e fora.

Ao esquema reflexo fisiológico, que tende ao afastamento dos estímulos externos, logo sobrevêm o afluxo dos estímulos internos, que exigem atividades complicadas e intrincadas. Diante deles, o sistema nervoso é obrigado a abdicar de sua função natural o afastamento dos estímulos externos. Esses exigentes estímulos internos, Freud (2015/1915) chama estímulos pulsionais. Suas características são: advir do interior do próprio organismo e atuar como uma força constante, uma força de caráter inexpugnável. Diante deles, produz-se também uma modificação no mundo externo, mundo esse que oferece satisfação à fonte dos estímulos pulsionais. Com Freud, somos impelidos a explorar essa transformação.

$\mathrm{Na}$ descrição do conceito de pulsão, Freud distingue alguns termos que a ele se relacionam: impulso (drang), alvo (ziel), objeto (objekt) e fonte (quelle). Tais termos nos esclarecem a relação supracitada. O impulso é o que dá a medida da exigência de trabalho. Nesse sentido, toda pulsão é ativa. Já o alvo, a meta, é sempre a satisfação, mesmo que diferentes caminhos a conduzam para um mesmo fim: a suspensão da estimulação da fonte pulsional. Todavia, pelo fato de haver uma variedade de caminhos, Freud (2015/1915) se permite falar em pulsão com meta passiva, pulsão inibida em sua meta, metas aproximadas, metas intermediárias. Esta meta, a satisfação, mesmo que parcial, é atingida através do objeto. Em sua origem, o objeto não está ligado à pulsão, ele só se liga a ela pela capacidade de levar à satisfação. Assim sendo, é o termo mais variável dentre os quatro.

O objeto pulsional não precisa ser um objeto material estranho/externo, pode ser uma parte do próprio corpo. Esse objeto é referente do objeto primeiro, perdido para sempre. Já a fonte parte de um processo somático para se tornar uma parte do corpo bordeada. Freud (2015/1915) a credita como elemento mais decisivo, mesmo não sendo de natureza psicológica. A fonte só se liga à vida anímica pela meta, de maneira que as pulsões podem ser inferidas de modo retrospectivo - atingindo-se o alvo. É o estímulo dessa parte do corpo, da fonte, que é passível de ser representado pela pulsão. É por meio da borda corporal, como a boca que suga o seio, que o seio vem a se inscrever no lugar do objeto que falta, pelo prazer outrora gerado na zona agora erógena, a boca, ao atingir parcialmente a satisfação. Todavia, lembremos do apoio da fonte em uma função vital. É onde a fome de alimento, campo da necessidade, transforma-se em boca que se abre para abocanhar o seio, objeto pulsional; que se desdobra todo um circuito capaz de engendrar o enganche do sujeito ao outro.

Considerados esses elementos e o caminho que tomará esse estudo, a voz que se manifesta enquanto apelo, partimos do apoio na função vital para questionar se haveria, no princípio, uma necessidade sonora capaz de impulsionar a voz ao estatuto de objeto da pulsão. Teríamos de registrar algo da ordem de uma apetência sonora já no nascimento? 
A vertente psicanalítica que seguimos neste escrito permite dizer que o que nasce é uma "libra de carne" (LACAN, 2005/1962-63). Mas não é um pedaço de carne qualquer, desde o princípio, percebe-se seu tropismo de voz. Como observa Vivès (2017), desde o nascimento, o infans vira a cabeça em direção à voz materna.

Pesquisas informam que, durante o primeiro mês de vida, os bebês discriminam a voz de sua mãe em relação às vozes de outras pessoas (KENT; MIOLO, 1997). Muito cedo, nas primeiras duas horas de vida, neonatos já são capazes de responder de forma seletiva à voz materna. Eles aumentam a atividade motora quando ouvem a voz da mãe, porém o mesmo não acontece quando ouvem vozes não familiares (QUERLEU et al., 1984).

A familiaridade, nestes estudos, é evocada pela sensibilidade auditiva que os bebês desenvolvem já no meio intrauterino. Mesmo que a criança só seja exposta ao espectro sonoro completo após o nascimento, as experiências pré-natais auxiliam a reconhecer alguns sons nas primeiras semanas de vida (WERNER, 2007). Aos quatro meses de gestação, o feto já ouve os sons provindos do exterior do corpo materno, de modo que esse ambiente sonoro preexiste ao nascimento. (MATIAS, 1999; NUNES, 2010). Com isso, é capaz de conhecer a voz materna, as músicas simples e os sons comuns ao ambiente (MOON; FIFER, 2000).

Não há nada de objeto psíquico nas pesquisas citadas acima, e não há nada de objeto materno ou qualquer outro no meio intrauterino, como observou Freud (2014/1926). Mas os estudos psicanalíticos apontam que o bebê, ao nascer, tem fome de voz, sustentando que o pequeno é um apetente simbólico (CATÃO, 2009; LAZNIK, 2004; VIVÈS, 2012). Este modo de tratar a sonoridade materna, como enganche simbólico, permite-nos questionar: de que voz se trata? Para tais autores, não é qualquer voz, para que o infans não se torne impassível diante da fala, é preciso que haja na voz materna algo bastante singular, uma prosódia ${ }^{1}$ singular, conhecida como manhês, mamanhês ou parenthese. ${ }^{2}$

Inicialmente apontada como uma fala adaptada às possibilidades linguísticas do infans, por suas especificidades fonéticas, léxicas e gramaticais (JAKOBSON, 1969/1941), destaca-se pelas modificações prosódicas em relação à fala dirigida aos adultos. Para Ferreira (2001), essas modificações são caracterizadas por elevação da frequência fundamental (higher picht), incidência de picos prosódicos, sintaxe simplificada, uso de diminutivos, evitação de encontros consonantais e repetição silábica.

Neste "exagero prosódico", considerado como uso espontâneo da musicalidade na fala dirigida à criança e aos bebês, também temos uma fala mais cadenciada, de ritmo diferenciado, sendo as pausas entre os enunciados mais longas, aspectos já evidenciados no estudo de Stern (2002/1977). Essa evidência rítmica da pulsação e da pausa, também é apontada por Weismer (1996), o qual enfatiza que, no mamanhês, há acentuação de mais de um elemento em uma frase e pausas que marcam mais previsivelmente as fronteiras de enunciados depois de cada frase ou palavra única.

\footnotetext{
${ }^{1}$ A prosódia refere-se ao ritmo, à entonação e à acentuação da língua quando falada.

${ }^{2}$ Este nome alusivo foi determinado ao final da década de 60 e refere-se a um tipo específico de fala que é dirigido pelas mães aos bebês ou às crianças pequenas.
} 
Mateus (2004) expõe que a prosódia é composta pelos traços e pelos constituintes, referindo-se aos primeiros como a medida do tempo (duração), as inflexões (o tom) e o acento (que tonaliza a voz), e aos segundos como a sílaba e a palavra. Focando nos traços prosódicos, diz que suas propriedades são inerentes ao som e estão relacionadas com as características acústicas das ondas sonoras. Ela descreve, então, as três propriedades: o tom ou frequência, a intensidade e a duração.

O tom tem como correlato acústico a frequência da onda sonora, o número de vezes que um ciclo completo de vibração das partículas se repete durante um segundo. Quanto maior o número de ciclos de vibração das partículas, maior é a altura do som, mais "alto" é o tom. A frequência fundamental relaciona-se com as cordas vocais: quanto mais delgadas, maior o número de vibrações, maior a altura do som. Uma sequência de segmentos com os seus respectivos tons cria a entoação dessa sequência, quer se trate de uma palavra ou de um grupo de palavras.

A intensidade do som, por sua vez, decorre da amplitude da onda sonora, o valor da distância entre a pressão zero e a pressão máxima da onda, diz a autora. Quanto maior for a amplitude de vibração das partículas, maior é a quantidade de energia transportada por estas e maior é a sensação auditiva de intensidade do som. A proeminência do som, chamada "acento", decorre dessa intensidade.

A terceira propriedade, a duração, refere-se ao tempo de articulação de um som, sílaba ou enunciado e tem uma importância fundamental no ritmo de cada língua. A duração de cada unidade varia conforme a velocidade de elocução, o que significa que, se a velocidade de produção for maior, a duração de cada elemento é menor (MATEUS, 2004).

Desse modo, duração, intensidade e frequência concorrem para a construção do ritmo das línguas e é esse aspecto que encontramos diferenciado no mamanhês. É a peculiaridade prosódica do mamanhês, voz rítmica e musical, que Catão (2009), Laznik (2004) e Vivès (2012) afirmam ser a fonte de encantamento do bebê ou a fonte pela qual ele se deixa fisgar. Seria esta voz a voz prosódica do mamanhês, a boa sonoridade recebida pelos bebês no juízo de atribuição? Qual seria a voz expulsa então? Essas questões se impuseram às autoras deste ensaio, junto à constatação de que, mesmo concorrendo com qualquer mamanhês, o timbre materno é o chamarisco mais potente no princípio da vida do bebê.

Enquanto um bebê com menos de um mês consegue reconhecer o timbre que torna peculiar a voz de sua mãe, é apenas entre um e quatro meses que reconhece variações em padrões entoacionais e diferentes ritmos de fala. Somente entre quatro e seis meses ele detecta marcadores prosódicos de unidades oracionais e tem uma preferência pelo mamanhês em relação à fala dirigida ao adulto (KENT; MIOLO, 1997).

Encontramos sustentação de nossa hipótese sobre o timbre materno nos desdobramentos atuais de Vivès (2016). Ele concorda que o infans reconhece o timbre muito cedo, como puderam mostrar as experiências de psicólogos geneticistas conduzidas com recém-nascidos de algumas horas de idade (Informação verbal ${ }^{3}$ ).

\footnotetext{
${ }^{3}$ Palestra apresentada por Jean-Michel Vivès, em Conferência na FCM-UNICAMP, na cidade de Campinas, em 29 de agosto de 2016.
}

PEREIRA, Amanda Schreiner; VORCARO, Angela Maria Resende; KESKE-SOARES, Marcia. Do discurso do agente do Outro à voz-apelo do sujeito. Linguagem em (Dis)curso - LemD, Tubarão, SC, v. 18, n. 2, p. 431-447, maio/ago. 2018. 
O timbre é uma voz natural, aquilo que é único, próprio a cada indivíduo, algo que informa em tempo normal sobre as qualidades de uma voz. Como vimos, dentre os parâmetros sonoros da qualidade da voz, temos: a altura, que permite dizer se um som é grave ou agudo; a duração, que define um som, num espaço de tempo, como curto ou longo; e o volume, cuja intensidade define se um som é delicado ou forte. Eles são medidos, respectivamente, em hertz, segundos e decibéis (VIVÈS, 2016, informação verbal).

Vivès (2016) trata o timbre como quarto parâmetro, justamente por ser incomensurável. Em seu caráter enigmático, o timbre escapa à possibilidade de ser totalmente cernido. Ele é tudo que faz com que um som produza a mesma altura, a mesma duração, a mesma intensidade de outro e não se pareça com ele. (Informação verbal).

O timbre resulta de um embaralhado complexo no qual outras frequências sonoras, como os harmônicos e as reverberações, vêm somar à frequência inicial. O timbre depende também do contorno temporal do som: ataque, queda, sustentação, extinção. Não se pode medir o timbre de determinado som, mas pode-se observar seu espectro sonoro com a ajuda de analisadores que identificam e permitem a visualização de diversas frequências a ele associadas. Assim, dois sons podem ter a mesma altura e a mesma potência, mas não podem ter o mesmo timbre, que depende da forma como é atacado e de ressonadores privilegiados (VIVÈS, 2016, informação verbal).

O timbre é o parâmetro vocal mais difícil de apreender: a potência e a altura podem ser medidos, mas não o timbre, ele é para a voz o equivalente das impressões digitais, por isso o chamamos impressão vocal. Este índice de presença poderoso, Vivès (2017) deve ser acolhido e, ao mesmo tempo, rejeitado.

Associaremos a rejeição do objeto primordial ao funcionamento prévio ao engajamento na linguagem. No juízo de atribuição, os objetos da satisfação da necessidade permitem à criança alojar-se em uma posição onde se inscreve o registro de uma diferença entre dois estados que se recobrem. Trata-se dos estados de satisfação/insatisfação inscritos como presença/ausência do outro assegurador.

No seminário 4, Lacan (1995/1956-57) diz que aqui temos a posição zero (0), a instauração dos símbolos puros de mais e de menos, tendo em vista que a presença está sob fundo da ausência, e a ausência na proporção em que constitui a presença. Esses sinais se determinam reciprocamente na relação diferencial em que se reenviam um ao outro. Para Jerusalisnky, J. (2004), observa-se esses movimentos recíprocos nas principais marcas do Outro no bebê, que inscrevem uma estrutura que supõe uma temporalidade ritmada das funções e da sua funcionalidade: fome-saciedade, sono-vigília, ritmicidade das vocalizações.

Segundo Vorcaro (1997, 2001, 2002, 2003, 2017), é essa temporalidade ritmada que sustenta a condição mínima para a possibilidade simbólica estrutural, uma vez que tais traços demarcam uma matriz simbólica que inaugura a condição de subjetivação. $O$ neonato e o outro funcionam simetricamente numa diferenciação ordenada e operada pela fala maternante. O outro lhe responde supondo, nela, um apelo. Utiliza o recurso tanto da modalização de sua fala, quanto de sua presença, apaziguando a criança. 
Aqui há o funcionamento binário dos dois estados: desaparecimento e retorno, modalizados como tensão-apaziguamento, que permitirão a cada um desses antecipar o outro. É numa dupla mínima de termos em relação diferencial, que a incidência da falta real do objeto da satisfação localiza um sistema de pontos singulares posicionando o impossível da automaticidade tensão-apaziguamento. O objeto de satisfação se esboça no simbólico ao emergir enquanto falta radical, essa é sua condição. Essa falta radical, essa privação, pode ser reduzida por meio de um acionamento vocal infans, constituindo um apelo à coisa alternante. Diante da hiância, o infans ocupará esta posição vazia pelo grito, que substitui o termo sustentador da alternância. O que evocamos é que podemos dimensionar a perda de dois objetos: o objeto/coisa, que outrora chamávamos de objeto da necessidade, cujo agente materno pode assegurar-lhe o retorno; e o despontar do objeto voz, que se perde pela passagem por um orifício que se abre no apelo infans.

Quanto ao objeto voz-grito, temos de analisá-lo pelas prerrogativas judicativas que expúnhamos há pouco. O que é cuspido no campo da voz? É esse grito, em sua condição de uma primeira inscrição, a apelativa. Abre-se em sua expulsão, em seu recurso de cuspe, um desdobramento: sua elevação ao segundo juízo.

Dissemos que o objetivo primeiro e imediato do teste de realidade não é encontrar na percepção real um objeto que corresponda ao representado, mas reencontrar tal objeto, certificar-se de que ele ainda está lá. A voz-apelo pode justamente sustentar a reativação de um objeto, reevocá-lo. Se pensarmos que, na associação entre a voz recuperadora do objeto, o grito infans se liga a uma imagem acústica capaz de reevocar tal objeto, teremos aqui certa formatação da voz/timbre, presta-se a significar algo para alguém. Temos aqui a formação da identidade perceptiva prosódica, que permite reconhecer os primeiros registros e amarrações da voz, deixando para traz o grito/timbre/resto.

\section{VOZ-APELO}

Falamos, na seção anterior, sobre a condição de privação a partir da qual acontece o movimento de elevação do grito infans à função de apelo. Lembremos que esse movimento é precedido da condição em que o Outro traça o primeiro grito infans como um apelo a si. Essa condição implica que o infans seja retirado, pelo agente do Outro, da condição de organismo, para tornar-se filho, articulado numa linhagem e numa história que o transpõe da natureza à cultura, ao mesmo tempo em que o priva do fluxo vital caótico, organizando-o como linguagem. O caráter de alternância da relação presençaausência, fica mais complexo nos valores sucessivos que o agente do Outro atribui às manifestações infans. O grito do bebê, mesmo ao se repetir idêntico, sem diferença fônica, avança para o Outro, uma vez que muda de valor a cada emissão (VORCARO, 1997).

Isso ocorre porque a significação dada pelo agente do Outro às manifestações do bebê é sustentada na linguagem. Jerusalinsky, A. (1999) afirma que é por isso que o agente interpreta os atos infans numa série onde questiona, por exemplo: o que veio antes do choro? Ou seja, a interpretação vale-se de um curso de ida e volta no tempo. A linguagem coloca um ordenamento simbólico que situa o lugar da criança no espaço de uma série que a significa. Desse modo, o objeto da demanda é ofertado do lugar Outro 
em meio à lógica da linguagem, numa leitura interpretativa do agente por retroação. Assim, avançamos sempre em direção à outra coisa - a hipótese de que se tratava de outra coisa que o bebê demandava está mantida.

Além disso, o objeto não chega ao mesmo tempo em que a criança o reclama. $\mathrm{O}$ próprio efeito do funcionamento ritmado da alternância faz incidir uma lacuna, uma alteridade real, na relação de alternância rítmica. Isso ocorre porque o infans já apreendeu que a mãe costuma reaparecer. O que se dá, conforme Freud (2014/1926), pelas repetidas experiências de aproximação e afastamento desta.

Como mostra Vorcaro (2001, 2017), essas experiências de aproximação e afastamento são acompanhadas da emissão vocal com a prosódia própria materna ou uma cantiga infantil, que demarcam um balanço. Essa prosódia é marca do ritmo das emissões no próprio corpo e é capaz de ressoar no corpo do bebê. É, assim, uma provocação que evoca movimentos e sons no corpo do infans, uma consonância ao andamento materno imposto à prosódia, à cantiga ou ao refrão reproduzido.

Jerusalinsky, J. (2009) permite que identifiquemos o enriquecimento das modulações vocais dos bebês a partir das alternâncias da prosódia materna. Desde os dois meses de idade do bebê, a mãe já silencia após convocá-lo, esperando que ele lhe retorne. Ferreira (1997) observa que, além de interpretar a vocalização dos bebês, a mãe também assume, alternadamente, as posições da troca dialógica (turn-talking), falando por ele. Esse revezamento manifesta a suposição de que o bebê tem algo a dizer, ou seja, sustenta uma alteridade. Para Jerusalinsky, J., a mãe dá, assim, voz ao bebê, tomando suas fonações como um chamado.

Vorcaro (2017) faz observar que mesmo as brincadeiras de separações, propostas pela mãe à criança, são acompanhadas de uma prosódia rítmica, entoadas de formas diversas de registro do desaparecimento "cadê? onde está?" e do reencontro "achou!". Ressaltamos que, mesmo em situações de cuidados cotidianos, a fala do agente do Outro acompanha seus atos em direção ao bebê, por exemplo: "vamos trocar a fraldinha?". A velocidade das pulsações ou o cantar em diferentes vozes também são variações incidentes nessa cena. Nessas variações, a criança é surpreendida, isso força um engajamento ativo no qual o neonato passa a esperar a surpresa (VORCARO, 2017).

Lembramos que o que sustenta essas variantes são o desejo do agente do Outro, desejo que comparece em meio às produções prosódicas, investidas de afeto em suas entonações. O que demarcamos neste momento do escrito é o estado de anseio pelo qual o sujeito será tomado diante dos intervalos dos enunciados lhe endereçados. Lacan avançará em direção ao intervalo significante, no qual "vige o desejo oferecido ao balizamento do sujeito na experiência do desejo do discurso do Outro, do primeiro Outro [...] a mãe, no caso" (LACAN, 1998/1964, p. 207). O desejo desse Outro está aquém do que ela diz, além do que faz surgir como sentido, na intimação que o Outro faz à criança por seu discurso, nos intervalos desse discurso.

Nos primados deste intervalo, observa-se a série psíquica das separações que a experiência de distanciamento da mãe franqueia, o que produz a distinção entre o desamparo primário e o posterior estado de anseio. Articulamos, aqui, a questão intervalar à antecipação. É em razão dos intervalos que foi possível prever que, depois de determinado som, aconteceria o movimento seguinte. 
Desse modo, temos a defasagem temporal na oferta do objeto, a primariedade das condições da alternância rítmica do objeto presente-ausente que faz incidir a lacuna. Com ela, há um terceiro termo entre infans e objeto da necessidade, que faz com que o primeiro grito possa ser transformado em grito-demanda infans. Ao mesmo tempo em que o grito infans é vetorizado pela demanda do Outro, temos a cedência de uma parte do corpo infans, um escape sonoro que pode ser constituído como perda/soltura.

Nessa cedência de uma parte do corpo infans, introduz-se a surpresa da separação de uma parte de si. O si aqui, bem cabe, não é eu, nem tu, não é Eu, nem outro, mas entre. $\mathrm{O}$ grito que se desprende passando por um orifício do corpo, pode se tornar apelo, substituindo um dos termos esperados na alternância da oferta objetal que trabalhamos na seção anterior.

Se o corpo infans ressoa o movimento prosódico materno, temos então a elevação de uma segunda potência. Na segmentação temporal rítmica do cuidador, uma substituição inesperada advém de um apressamento ou de uma lentificação do andamento. Isso porque o encontro faltoso que marca a exclusão de um dos termos diferenciais delimita uma fissura na alternância, pelo adiamento ou pela precipitação dos termos alternantes (VORCARO, 1997, 2017).

Podemos incluir aqui a questão do silêncio no movimento prosódico/musical materno. Para Porge (2012, 2014), o discurso, desde o lugar do Outro, pode ser portador de um valor - pulsional - pela escolha dos termos, por sua sonoridade, pelo ritmo das frases e também por seus silêncios. O silêncio é uma pausa no discurso, da qual se sente a duração, ele introduz a dimensão temporal. Ele pode ser um ponto morto, mas também ter o valor de uma escansão, uma precipitação, um relance. Na música, o silêncio se chama síncope e é contado e grafado, localizado no compasso como notas. Esse silêncio sincopado é o que permite a antecipação na pressa. Porge esclarece que a pressa é a iminência do tempo de avanço possível do outro, tempo que não se mede e que é concorrência com o outro.

É pelo estado de anseio instaurado a partir da expectativa de reencontro que o bebê pode tornar seu grito apelo. Esse grito-apelo é originado no grito infans que, expulso, pôde entrar no movimento de reencontro representativo, resquício de um objeto indizível. O que se desprende como grito faz dessa emissão o que não se pode dizer.

Podemos pensar que é na simultaneidade na qual o timbre materno dá lugar à prosódia, com suas continuidades e seus intervalos, que o valor índice em que o grito infans faz-se apelo marca um sujeito em vias de constituir-se pela linguagem, no que a marca comparece, advertindo o que não está lá onde se esperava. Essa voz apelativa ressoa prosodicamente fazendo corpo infans. Temos aqui uma forma peculiar de identificação, a incorporação (LACAN, 2005/1962-63). A partir disso, a voz toma corpo com empréstimos de recursos da língua, para engajar-se no funcionamento da linguagem, na medida em que o sujeito vai em busca da possibilidade de tradução de seu anseio. 
Iniciamos pela voz sonorizada materna e pela precocidade dos sentidos auditivos no meio intrauterino. Aos quatro meses, no ventre materno, o feto já é capaz de ouvir a voz sonorizada; isso sustentaria que, ao nascer, o bebê já estivesse apto a reconhecê-la. Perguntamo-nos se a aptidão estaria ligada a essa precocidade sensitiva da voz e se haveria função vital relativa à voz. Tal função fora sustentada pela apetência simbólica infans ao mamanhês (CATÃO, 2009; LAZNIK, 2004; VIVÈS, 2012), língua peculiar, falada com bebês e crianças, com características musicais.

O chamarisco, porém, pareceu-nos originar-se em outro lugar. Há um mundo que se constitui entre a função vital, a extensão ventre-nascimento e a apetência simbólica. Foi nesse sentido que nosso ensaio permitiu restituir o timbre da voz. Antes que seja um apetente simbólico e antes que haja apetência sonora pela prosódia do mamanhês, é preciso que um timbre caia. É preciso que ele seja expulso para dar lugar à busca do reencontro faltoso, que irá permitir o movimento pulsional de enlace ao Outro.

Foi a leitura da voz, ejetada pelo grito infans, que permitiu que, no lugar do timbre materno, da onipresença, surgisse a presença-ausência autentificada pela musicalidade específica na qual aparece e desaparece a voz que dá lugar à primariedade rítmica. Traçamos o duplo movimento: a expulsão do timbre e a afirmação prosódica.

Tal afirmação permite ao infans ser sugado pela voz materna e ter apetência pela própria voz como aquela capaz de constituir laço com o Outro. Passando pela produção da voz-apelo, o infans esforça-se para corporificar as características melodiosas, o que é esboçado nos primeiros balbucios dos bebês. Nessas simples aproximações, como Lacan (2005/1953) chamou os balbucios, iniciam-se os movimentos de amarração à língua. Língua que comparece advertida do funcionamento simbólico da estrutura constitutiva do sujeito pela linguagem.

Desse modo, não foi apenas o grito infans perdido como objeto por trás do que ele significa no Outro, que fez da voz um objeto primordialmente perdido. Consideramos que o corte da abertura labial pela qual um princípio de sujeito se põe a expulsar uma parte de si, dando lugar ao apelo, é o determinante da primeira perda e de seu efeito corporal, em que mergulha a dimensão emissível da voz.

$\mathrm{Na}$ queda do primeiro grito e em sua transformação em voz-apelo, vislumbramos a origem da possível escolha infans como apetente simbólico, apetência pela própria voz como aquela que pode enganchar-se ao funcionamento da linguagem, frente a sua amarração imaginária à língua. Entretanto, a efetividade dos desdobramentos simbólicos a partir dessa incorporação primária da voz dependerá dos efeitos da experiência especular ainda por vir (LACAN, 1998/1949, 1998/1960). 
BERGÈS, J.; BALBO, G. Jogo de posições da mãe e da criança: ensaio sobre o transitivismo. Porto Alegre: CMC Editora, 2002.

CATÃO, I. O bebê nasce pela boca: voz, sujeito e clínica do autismo. São Paulo: Instituto Langage, 2009.

FERREIRA, S.S.M.O. A interação mãe-bebê: primeiros passos. In: WANDERLEY, D.B. (Org.) Palavras em torno do berço. Salvador: Ágalma, 1997. p. 77-88.

Por que falar ao bebê se ele não compreende? In: CAMAROTTI, M. C. (Org.). Atendimento ao bebê: uma abordagem interdisciplinar. São Paulo: Casa do Psicólogo, 2001. p. 97-103.

FREUD, S. Projeto para uma psicologia científica. In: Obras Psicológicas Completas de Sigmund Freud: edição standart brasileira, v.1, Publicações pré-psicanalíticas e esboços no prelo (18861889). Rio de Janeiro: Imago, 1996 (1895). p. 341-466.

Carta 112 [52], de 6 de dezembro de 1896. In: Obras Incompletas de Sigmund Freud, v.5, Neurose, Psicose, Perversão. Belo Horizonte: Autêntica Editora, 2016 (1896). p. 35-45.

. A Interpretação dos Sonhos. Trad. Renato Zwick. Porto Alegre: L\&PM Editores, 2016 (1900).

Formulações sobre os dois princípios do funcionamento psíquico. In: Obras completas,

v. 10, Observações psicanalíticas sobre um caso de paranoia relatado em autobiografia ("O caso Schreber”), artigos sobre a técnica e outros textos [1911-1913]. Trad. Paulo César de Souza. São Paulo: Companhia das Letras, 2010 (1911), p. 108-121.

. Introdução ao Narcisismo. Trad. Luís Fernando Lofrano de Oliveira, Max de Araújo Götze e Sofia Schneider. Revista da Associação Psicanalítica de Porto Alegre, Porto Alegre, v. 1, n. 47, p. 172193, jul./dez., 2014 (1914).

. As pulsões e seus destinos. In: . As pulsões e seus destinos. Edição Bilíngue. Trad. Pedro Heliodoro Tavares. Belo Horizonte: Autêntica Editora, 2015 (1915), p. 13-69.

Além do Princípio do Prazer. In: Obras Completas, v. 14, História de uma neurose infantil: ("O homem dos lobos"), além do princípio do prazer e outros textos [1917-1920]. Trad. Paulo César de Souza. São Paulo: Companhia das Letras, 2010 (1920), p. 161-239.

O eu e o id. In: Obras Completas, v. 16, O eu e o id, "autobiografia" e outros textos [1923-1925]. Trad. Paulo César de Souza. São Paulo: Companhia das Letras, 2011(1923), p. 13-74. A Negação. In: Obras Completas, v. 16, O eu e o id, "autobiografia" e outros textos [1923-1925]. Trad. Paulo César de Souza. São Paulo: Companhia das Letras, 2011(1925), p. 275-282.

Inibição, Sintoma e Angústia. In: Obras Completas, v. 17, Inibição, Sintoma e Angústia o futuro de uma ilusão e outros textos [1926-1929]. Trad. Paulo César de Souza. São Paulo: Companhia das Letras, 2014 (1926), p. 13-123.

JAKOBSON, R. Lenguaje infantil y afasia. Buenos Aires: Ayuso, 1969 (1941).

JERUSALINSKY, A. Desenvolvimento e Psicanálise. In: e col. Psicanálise e Desenvolvimento Infantil. 2. ed. revista e ampliada. POA: Artes e Ofícios, 1999, p. 23-31.

JERUSALINSKY, A. Saber falar. Como se adquire a língua? 2. ed. Petrópolis, RJ: Vozes, 2008.

JERUSALINSKY, J. Prosódia e enunciação na clínica com bebês: quando a entoação diz mais do que se queria dizer. In: VORCARO, A.M.R. (Org.). Quem fala na língua? Sobre as psicopatologias de fala. Salvador: Ágalma, 2004. p. 13-19

A criação da criança: letra e gozo nos primórdios do psiquismo. 2009. 262 p. Tese (Doutorado em Psicologia Clínica) - Pontifícia Universidade Católica de São Paulo, São Paulo, SP, 2009.

KENT, R. D.; MIOLO, G. Habilidades Fonéticas no Primeiro Ano de Vida. In: FLETCHER, P.; MACWHINNEY, B. Compêndio de Linguagem da Criança. Porto Alegre: Artes Médicas, 1997. p. 253276.

LACAN, J. O estádio do espelho como formador da função do eu. In: Escritos. Rio de Janeiro:

Zahar, 1998 (1949). p. 96-103

O Seminário. Livro 4. A relação de objeto. Rio de Janeiro: Zahar, 1995 (1956/1957).

O Seminário. Livro 7. A ética da psicanálise. Rio de Janeiro: Zahar, 2008 (1959/1960).

PEREIRA, Amanda Schreiner; VORCARO, Angela Maria Resende; KESKE-SOARES, Marcia. Do discurso do agente do Outro à voz-apelo do sujeito. Linguagem em (Dis)curso - LemD, Tubarão, SC, v. 18, n. 2, p. 431-447, maio/ago. 2018. 
Observação sobre o relatório de Daniel Lagache: "Psicanálise e estrutura de personalidade". In: Escritos. Rio de Janeiro: Zahar, 1998 (1960). p. 653-691.

O Seminário Livro 10. A Angústia. Rio de Janeiro: Zahar, 2005 (1962/1963).

$55-87$.

Introdução aos Nomes-do-Pai. In:

Nomes-do-Pai. Rio de Janeiro: Zahar, 2005 (1963), p.

O Seminário Livro 11. Os quatro conceitos fundamentais da psicanálise. 2. ed. Rio de Janeiro:

Zahar, 1998 (1964).

LAZNIK, M. C. A voz da sereia. O autismo e os impasses na constituição do sujeito. Salvador: Ágalma, 2004.

MATEUS, M.H.M. Estudando a melodia da fala: traços prosódicos e constituintes prosódicos. In:

Encontro da APL e ESE de Setúbal. o Ensino das Línguas e a Linguística, 2004, Setúbal, Anais

Eletrônicos. Setúbal: ESE, 2004, Disponível em: <http://www.iltec.pt/pdf/wpapers/2004-mhmateusprosodia.pdf>. Acesso em: 28 jul. 2014.

MATIAS, G. F. A. A importância da estimulação auditiva durante o período pré e pós-natal. 1999. $23 \mathrm{f}$. Monografia (Especialização em Audiologia Clínica) - Centro de Especialização em Audiologia Clínica, Goiânia, GO, 1999.

MOON, C., FIFER, W.P. Evidence of transnatal auditory learning. Journal of Perinatology, n. 20 v. 8, p. 37-44, dez. 2000. Disponível em: <https://www.ncbi.nlm.nih.gov/pubmed/11190699> Acesso em: 21 abr. 2017.

NUNES, P. A. O. Experiência auditiva no meio intrauterino. Psicologia.com.pt O portal dos Psicólogos. p. 1-15, jan. 2010. Disponível em: <http://www.psicologia.pt/artigos/textos/TL0157.pdf.> Acesso em: 21 abr. 2017.

PORGE, E. Voz do eco = Voix de l'écho. Campinas, SP: Mercado das Letras, 2014; Toulouse: Érès, 2012.

QUERLEU, D. et al. Reactivité du nouveau-né de moins de deux heures de vie à la voix maternelle. Journal de Gynécologie Obstétrique et Biologie de la Reproduction, Paris, v. 2, n. 13, p. 125-35, 1984. Disponível em: <https://www.ncbi.nlm.nih.gov/pubmed/6736589> Acesso em: 21 abr. 2017.

QUINET, A. Um olhar a mais. Ver e ser visto em psicanálise. 2. ed. Rio de Janeiro: Zahar, 2004.

SEGANFREDO, G. F. C.; CHATELARD, D. S. Das Ding: o mais primitivo dos êxtimos. Cadernos de Psicanálise - CPRJ, Rio de Janeiro, v. 36, n. 30, p. 61-70, jan./jun. 2014. Disponível. em:

$<$ http://cprj.com.br/imagenscadernos/caderno30_pdf/05_Das_Ding_o_mais_primitivo_dos_extimos.pdf >. Acesso em: 6 abr. 2017.

STERN, D. The first relationship: Mother and infant. Edição on-line. Cambridge, MA: Harvard University Press, 2002 (1977). Disponível em: <http://www.abebe.org.br/wp-content/uploads/Daniel-N.Stern-The-First-Relationship-Infant-and-Mother-With-a-New-Introduction-2002-1.pdf.>. Acesso em: 06 abr. 2017.

VIVÈS, J. M. A voz na clínica psicanalítica. Tradução: Vera Avellar Ribeiro. Rio de Janeiro: Contracapa, 2012.

O que ouvimos quando nos ouvimos? In: MALISKA, M. E.; SOUZA, P. (Org.). Abordagens da voz a partir da Análise de Discurso e da Psicanálise. Campinas: Pontes Editores, 2017. p. 17-37.

Autismo e voz maquínica. Conferência na FCM-UNICAMP, Campinas, agosto de 2016.

VORCARO, A.M.R. Sob a vigência da linguagem: uma aproximação à clínica psicanalítica de crianças, 1997, 198 f. Tese (Doutorado em Psicologia Clínica) - Pontifícia Universidade Católica de São Paulo, São Paulo, SP, 1997.

Incidência da matriz simbolizante no organismo: o advento da fala. Letras de Hoje, v. 36, n. 3,

Porto Alegre, p. 273-281, 2001.

Linguagem maternante e língua materna: sobre o funcionamento lingüístico que precede a fala.

In: BERNARDINO, L.; ROHENKOHL, C. (Org.). O bebê a modernidade, abordagens teórico-clínicas. São Paulo: Casa do Psicólogo, 2002. p. 65-84.

Os dragões do tempo primordial: a repetição como primeira identificação. In: LEITE, N. V. A. (Org.). Corpolinguagem: gestos e afetos. Campinas: Mercado de Letras, 2003. p. 215-231

Um refrão surdo ressoa no corpo. In: BURGARELI, C. G.; NOVA, M. (Org.). Padecer do significante: a questão do sujeito. Goiânia: Editora UFG, 2017. p. 115-147.

PEREIRA, Amanda Schreiner; VORCARO, Angela Maria Resende; KESKE-SOARES, Marcia. Do discurso do agente do Outro à voz-apelo do sujeito. Linguagem em (Dis)curso - LemD, Tubarão, SC, v. 18, n. 2, p. 431-447, maio/ago. 2018. 
WEISMER, S. E. O papel das variantes prosódicas no processamento linguístico de crianças com impedimentos específicos de linguagem. In: CHAPMAN, R. S. Processos e distúrbios na aquisição da linguagem. Porto Alegre: Artes Médicas, 1996. p. 125-134.

WERNER, L.A. Issues in human auditory development. Journal of Communication Disorders. v. 4, n. 40, p. 275-283, jul./ago. 2007. Disponível em:

<https://www.ncbi.nlm.nih.gov/pmc/articles/PMC1975821/>. Acesso em: 21 abr. 2017.

Recebido em: 21/08/17. Aprovado em: 08/04/18.

Title: From the discourse of the Other to the voice-appeal of the subject

Authors: Amanda Schreiner Pereira; Angela Maria Resende Vorcaro; Marcia Keske-Soares

Abstract: This paper is a theoretical-critical psychoanalytical research based upon the readings on Freud and Lacan, as well as in the snippets provided by the authors to associate the origin of the voice-appeal of the subject to the discourse of the Other, supported by the logics of language. The expulsion of the timbre, the affirmation of the maternal prosodic voice and the establishment of the first symbolic matrix in infants are highlighted from the addressing of agent of the Other. Whatsoever, it places the subject by the relation with the maternal speech and emphasizes the passage from the initial cries to the voice that makes appeal through the engagement in the bond with the Other.

Keywords: Speech. Other. Voice. Subject.

Título: Del discurso del agente del Otro hasta la voz-apelación del sujeto

Autoras: Amanda Schreiner Pereira; Angela Maria Resende Vorcaro; Marcia Keske-Soares

Resumen: Este artículo es un estudio teórico-crítico psicoanalítico basado en la lectura de la obra de Freud y de Lacan y en los recortes emprendidos por las autoras para asociar el origen de la voz-apelación del sujeto al discurso del agente del Otro, sostenido por la lógica del lenguaje. De los direccionamientos del agente del Otro, despega la expulsión del timbre, la afirmación de la voz prosódica maternal y la instauración de la primera matriz que simboliza en el infans. Con ello, posiciona el sujeto, desde los principios, por la relación con el discurso maternal y enfatiza el pasaje de los vagidos iniciales hasta la voz que hace apelación, por medio del encajamiento en el lazo con el Otro.

Palabras clave: Discurso. Otro. Voz. Sujeto.

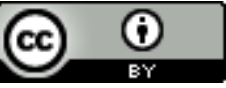

Este texto está licenciado com uma Licença Creative Commons Atribuição 4.0 Internacional.

PEREIRA, Amanda Schreiner; VORCARO, Angela Maria Resende; KESKE-SOARES, Marcia. Do discurso do agente do Outro à voz-apelo do sujeito. Linguagem em (Dis)curso - LemD, Tubarão, SC, v. 18, n. 2, p. 431-447, maio/ago. 2018. 